\title{
Should bariatric surgery be performed in adolescents?
}

\author{
Andrew J Beamish ${ }^{1,2}$ and Thomas Reinehr ${ }^{3}$ \\ ${ }^{1}$ Department of Gastrosurgical Research, Institute of Clinical Sciences, Gothenburg University, \\ Gothenburg, Sweden, ${ }^{2}$ Research Department, The Royal College of Surgeons of England, London, UK, \\ and ${ }^{3}$ Vestische Hospital for Children and Adolescents University of Witten/Herdecke Department of \\ Pediatric Endocrinology, Diabetes, and Nutrition Medicine, Datteln, Germany
}

Correspondence should be addressed to T Reinehr Email

T.Reinehr@kinderklinikdatteln.de

\begin{abstract}
Adolescent obesity has markedly increased worldwide in both its extent and prevalence in recent decades and obesity prevention strategies are failing. As a result, effective treatment strategies are urgently needed. As behavioral and pharmacological treatment approaches have only moderate effects in severe obesity, bariatric surgery has begun to emerge as a treatment option. In this debate article, we offer arguments opposing and supporting bariatric surgery in the treatment of severe obesity in adolescents. Bariatric surgery has superior therapeutic outcomes with respect to weight loss and resolution of comorbid diseases over other existing treatments. However, long-term outcomes after bariatric surgery in adolescents are only just beginning to emerge. Furthermore, the procedures are generally considered irreversible, apart from gastric banding. Most importantly, not all adolescents seem to benefit greatly from bariatric surgery and we are not yet able to reliably identify those who stand to gain the greatest benefit. The authors agree that adolescent bariatric surgery should be offered exclusively within formal adolescent obesity programs, delivered by specialist multidisciplinary child/adolescent obesity teams, and within specialist centers, in order to optimize outcomes and minimize potential detrimental effects. Patients and their family/carers must be educated regarding the benefits and risks, potential side effects, expected changes in eating behavior and the lifelong requirement for regular medical follow-up after surgery. Before embarking upon a surgical treatment pathway in adolescents with severe obesity, it may also be beneficial to ensure compliance to treatment is demonstrated, in order to minimize the risk of nutritional deficiencies and associated potential complications.

European Journal of Endocrinology (2017) 176, D1-D15
\end{abstract}

\section{Introduction}

Adolescent obesity has markedly increased in prevalence worldwide across the past three decades (1, 2, 3, 4). In the adolescent, obesity is associated with type 2 diabetes, increased cardiovascular risk $(5,6,7)$ and early cardiovascular changes $(6,8)$. Furthermore, obesity in adolescents leads to a reduction in quality of life and global functional impairment $(9,10,11,12)$. Therefore, effective treatment strategies are urgently needed.

Many studies have cataloged the modest outcomes of conventional treatment for adolescent obesity, including behavioral and pharmacological approaches, which are mostly confined to the short term $(13,14,15)$. Thus, bariatric surgery has emerged as a potential treatment
(C) 2017 European Society of Endocrinology Printed in Great Britain option, and the number of adolescents undergoing bariatric surgery is increasing in Europe (16), the United States (17) and beyond (18).

In this debate article, we offer arguments opposing and supporting bariatric surgery in the treatment of adolescent obesity.

\section{The case against bariatric surgery for adolescent obesity}

Weight loss is much greater in patients after bariatric surgery compared to patients with lifestyle intervention $(19,20,21,22)$. Quality of life and other psychological

Published by Bioscientifica Ltd. 
Table 1 Reported side effects of bariatric surgery in adolescents.

\begin{tabular}{lcc} 
Outcome & & $\begin{array}{c}\text { Adolescent bariatric surgery } \\
(\%)(16,21,22,26,27,80)\end{array}$ \\
\cline { 1 - 2 } Mortality (30-day) & 0 \\
Additional operations & $3-48$ \\
Low ferritin & $13-17 *$ \\
Low folate & $39-57$ \\
Low vitamin $\mathrm{B}_{12}$ & 8 \\
Low vitamin D (25-OHD) & $8-13$ \\
Low vitamin A & 43 \\
\hline
\end{tabular}

\begin{tabular}{c} 
Adult bariatric surgery \\
(\%) $(101,114,141,142,143,144)$ \\
\hline $0.08-0.31$ \\
$10-17$ \\
$6-7^{\star}$ \\
$23.5-28$ \\
$16-35$ \\
$58-61.8$ \\
52 \\
17
\end{tabular}

Healthy adolescent population

(\%) $(22,113,145,146)$

N/A
N/A
-
21
53
0
42
$6^{\wedge}$

${ }^{\circ}$ One case reported as a stand alone case report in the literature; *excluding gastric band explantation, which has been reported in approximately a quarter of adolescents and half of adults; ^^preoperative adolescent obesity group.

outcomes frequently improve after bariatric surgery (23, $24)$, and its short-term side effects and mortality are low in specialized centers $(16,19,20,21,22)$. However, there are some concerns regarding bariatric surgery in adolescents. These mainly relate to side effects, uncertainty about longterm outcomes and ethical considerations surrounding adolescents agreeing to bariatric surgery procedures, which are predominantly irreversible.

The known side effects of bariatric surgery in adolescents are largely informed by four registries of bariatric surgery in adolescents: the Teen-Longitudinal Assessment of Bariatric Surgery (Teen-LABS) study from the United States $(22,25,26)$, Adolescent Morbid Obesity Surgery (AMOS) study in Sweden (27), the Germany Obesity Registry (16) and a series from Saudi Arabia (18). The known complications are summarized in Table 1. In the first three years after bariatric surgery, the number of side effects is relatively low. However, it should be mentioned that the low complication rates in bariatric surgery in adolescents in these registries are derived from highly experienced surgeons. Owing to the effect of a learning curve in surgical procedures, centers planning to initiate bariatric surgery in adolescents should ensure that the operating surgeons are of sufficient experience, much of which may be from surgery in adults, to minimize the impact of their learning curve on the mortality and morbidity outcomes of operated adolescents. Dualoperating between pediatric and adult bariatric surgeons should be considered.

It has to be highlighted that one perioperative death has been reported in the literature (28), demonstrating that the mortality is above zero. Subsequent bariatric surgery procedures are frequently necessary, especially after gastric banding (21). Most importantly, the morbidity and mortality after 3 years are currently unknown. However, it can be expected that severe side effects will occur in some patients, especially after the more invasive procedures.
An example side effect is the dumping syndrome, which comprises a combination of gastrointestinalsymptoms, such as abdominal pain, diarrhea, nausea, bloating, alongside vasomotor symptoms, such as fatigue, palpitations and hypotension (29). The dumping syndrome is divided into early dumping, with gastrointestinal symptoms, and late dumping, typically occurring $1-3 \mathrm{~h}$ after a meal without gastrointestinal symptoms (30). Dumping has been reported in adolescents after Roux-en-Y bypass (31, 32). Furthermore, all techniques involve a risk of vitamin and micronutrient deficiency, which some worry could lead to a degree of growth retardation. The prevalence of decreased vitamin levels and ferritin levels in the first 3 years after bariatric surgery points in this direction (Table 1). Supplementation of vitamins and micronutrients is routine, especially after sleeve gastrectomy and gastric bypass procedures, to avoid rare irreversible side effects such as polyneuropathy associated with vitamin B12 deficiency (33). Finally, refeeding syndrome with Wernicke's encephalopathy, due to thiamine deficiency has been reported after obesity surgery (34), although it is exceptionally rare (33). Refeeding syndrome is an important complication of parenteral or enteral resumption of nutrition after malnourishment and reflects the change from catabolic to anabolic metabolism. It presents with a fall in serum levels of phosphate, potassium and magnesium. This severe electrolyte disturbance can cause a life-threatening condition, and early recognition is vital to reduce morbidity and mortality (35). Prevalence data in adolescents with bariatric surgery are not known so far. To detect these important side effects of bariatric surgery, regular check-ups of vitamin, electrolytes and hemoglobin levels are necessary. Therefore, lifelong treatment adherence is an important requirement for successful long-term intervention with bariatric surgery.

After bariatric surgery, eating behavior has to change toward consuming small portions. Additionally, sparkling 
Table 2 Arguments against bariatric surgery.

Argument against bariatric surgery
In adolescents with non-severe obesity, lifestyle interve
are effective to improve cardiovascular risk factors and
of life with few side effects
The long-term ( $>3$ years) effects of bariatric surgery on
mortality and morbidity have yet to be quantified

The long-term ( $>3$ years) effects of bariatric surgery on micronutrient and vitamin deficiencies are not known

The long-term ( $>3$ years) effects of bariatric surgery on the risk of development of other disease processes, pathological eating behavior or other relevant side effects have not yet been reported robustly

The long-term ( $>3$ years) effects of bariatric surgery on quality of life have yet to be quantified

We do not know which adolescents stand to benefit most from bariatric surgery and not all adolescents benefit psychologically from bariatric surgery

The prevalence of eating disorders and other psychiatric diseases among adolescents with severe obesity is not well quantified and, if uncontrolled, these may represent relative contraindications for bariatric surgery

Many adolescents are unable to adhere to the lifestyle interventions that guidelines state should be followed prior to entry into bariatric surgery programs. This raises a question of whether such individuals are truly eligible for surgery, in line with guidance

drinks should be avoided to minimize symptoms risk of gastroesophageal reflux and the potential for esophagitis after sleeve gastrectomy and gastric banding (36). Furthermore, esophagitis is a risk factor for esophageal cancer and adenocarcinoma of the gastroesophageal junction has been reported after bariatric surgery (37).

In the context of avoiding large food portions because of associated malaise, development of pathological eating behavior has been reported occasionally after bariatric surgery, especially when eating is an 'addiction'. Examples of this include consuming large volumes of high-caloric drinks or drinking melted chocolate. So far reports suggest that eating behavior adapts in a healthy direction after bariatric surgery in adolescents (38). However, it is unknown if this is true for all adolescents receiving bariatric surgery. It is likely that, especially in adolescents with eating disorders based on deteriorations in the satiety regulation such as melanocortin 4 receptor (MC4R) mutation, leptin resistance or PraderWilli syndrome (PWS), the eating behavior will not

\section{Counter-argument}

Adolescents with non-severe obesity are ineligible for bariatric surgery

A mature body of literature demonstrates overwhelmingly positive long-term implications on mortality and morbidity after bariatric surgery in adults. The growing body of literature in adolescents concurs thus far. Robust $\geq 5$-year European (AMOS) and US (FABS5+) adolescent outcomes are imminent

Many nutritional abnormalities are present in non-surgical adolescents with obesity, but additional deficiencies arise after bariatric surgery. The adult literature demonstrates that these are rarely irreversible. Careful monitoring and supplementation are essential core components of a bariatric surgical program

The adult literature demonstrates a $30-80 \%$ reduction in cancer risk after bariatric surgery within just 5-10 years of follow-up. In adults and adolescents, pathological eating appears uncommon and side effects have been well tolerated Outcomes in the short and medium term have been promising. Two major studies (AMOS and FABS5+) will imminently publish quality of life outcomes at $\geq 5$ years

Most adolescents gain significant physical and psychological benefit from their bariatric surgery. We must continue to actively seek ways of identifying those who will do well and those who will either need additional support or in whom surgery may be inappropriate

Reports in adolescent bariatric surgery describe careful psychological and dietetic assessment. Guidance is explicit in its eligibility requirement that any psychiatric condition must be under control

Guidance requires that candidates demonstrate an ability to comply with treatment regimens and medical therapy. Those failing to do so are considered ineligible for bariatric surgery

be normalized after bariatric surgery. Therefore, these adolescents may be at high risk for suboptimal weight loss or possibly even continued weight gain after bariatric surgery. Furthermore, if eating is restricted as a result of surgery, these adolescents may experience deterioration of their quality of life.

Of interest, there were two cases of attempted suicide reported after bariatric surgery in the AMOS study in Sweden $(23,39)$. Furthermore, not all adolescents demonstrated improved anxiety scores and improved depression scores after bariatric surgery in this registry $(23,39)$. Sixteen percent of the adolescents treated with bariatric surgery had deteriorated on two or more inventories in the Beck Youth Inventory (BYI) $(23,39)$. Additionally, five cases of drug abusers were reported after bariatric surgery $(23,39)$. These findings suggest that not all adolescents benefit psychologically from bariatric surgery. Therefore, screening potential candidates before the irreversible procedure of bariatric surgery seems appropriate to identify those adolescents who will 
benefit most from this kind of intervention. However, instruments to accurately elucidate this pre-operatively are not yet available.

Apart from the known side effects of bariatric surgery in adolescents, there may be further side effects in the long run, of which we have yet to become aware as these procedures were not performed 30 years ago in adolescents. Observations in adults show that the prevalence of some diseases can be greater several years after bariatric surgery than that in control patients, an example being renal lithiasis (40), although it should also be mentioned that data thus far suggest that bariatric surgery improves renal function in adolescents, at least in the short term (41).

Overall, three areas in bariatric surgery in adolescents raise ethical issues: the long-term morbidity and mortality are unknown as yet; apart from gastric banding, the procedures are irreversible and most importantly, not all adolescents seem to benefit from these procedures (see Table 2; (20)).

To evaluate whether the impressive effects of bariatric surgery on weight loss in adolescents with obesity justify the known and suspected side effects, it is necessary to compare the effects and side effects between bariatric surgery and lifestyle interventions. Lifestyle interventions based on behavioral strategies are regarded as the therapy of choice in adolescents with obesity (42). The efficiency of lifestyle intervention for childhood and adolescence obesity has been proven by several randomized controlled trials (RCT) and meta-analyses (42). Two meta-analyses summarizing the findings of $>60$ RCTs with $>5500$ children reported in concordance that combined behavioral lifestyle interventions are more effective in reducing obesity in children than standard care or self-help at 6and 12 -month follow-up $(43,44)$. The mean reduction of body mass index standard deviation score (BMI-SDS) in lifestyle interventions for children with obesity 12 months after onset of intervention ranged from -0.29 to -0.63 , with better results in children aged 8-12 years and those being less overweight $(43,44,45,46,47,48)$. The BMI reduction is much lower in lifestyle intervention than that in bariatric surgery $(19,20,21,22)$. Although long-term outcome data after bariatric surgery are missing, there are few studies in children and adolescents demonstrating the changes of weight status $\geq 5$ years after end of lifestyle intervention. However, consensus from existing longterm studies suggests that the weight loss achieved in the lifestyle intervention was sustained for $5-10$ years $(43,49$, $50,51)$. Lifestyle interventions in children and adolescents have been reported to be associated with an improvement of cardiovascular risk factors such as the components of the metabolic syndrome: hypertension, dyslipidemia and disturbed glucose metabolism $(52,53)$. Interestingly, cardiovascular risk factors ameliorated to a similar degree in the only existing randomized trial comparing bariatric surgery (adjustable gastric band) and a lifestyle intervention, even though weight loss was much greater in the gastric banding group (21). Non-alcoholic fatty liver disease (NAFLD) improves after lifestyle intervention (54), transaminase levels falling almost as much as has been observed after RYGB (27). Polycystic ovarian syndrome (PCOS) has also been shown to improve after a lifestyle intervention (54), evidence of which is limited thus far after bariatric surgery (55). Moreover, quality of life ameliorated in lifestyle interventions independently from the degree of weight loss $(56,57)$ and similar to the effects of bariatric surgery (23). One perioperative death has been reported after adolescent bariatric surgery (28), and three patient deaths, reportedly unrelated to the surgical procedure, have been documented in the long term $(22,55)$. In contrast, no mortality has been reported in lifestyle interventions $(43,44)$. Growth failure in weight loss attributable to lifestyle intervention has been excluded, and few studies have reported eating disorders in association with lifestyle interventions, the great majority of studies reporting no side effects (43, $44,58)$. However, unsuccessful participation in a lifestyle intervention could reduce participants' self-confidence because the adolescent with obesity learns that they cannot lose weight.

Beyond considering the evidence from randomized trials and meta-analyses of a considerable effect of lifestyle intervention on BMI and cardiovascular risk factors in children with obesity, some important concerns in everyday practice should be mentioned. Most adolescents with obesity do not want to participate in lifestyle interventions (59). The success rate (as defined by a reduction of $>0.25$ BMI-SDS) of 129 centers in Europe specialized in outpatient pediatric obesity care and treating $>20,000$ children with obesity was just $7 \%$ after 24 months in an intention-to-treat analysis (48). Most participants (92\%) were lost to follow-up in this study. However, in this observational study, some treatment centers achieved a success rate of $\sim 50 \%$, which demonstrates the great heterogeneity in the success rate. Of interest, the treatment centers with the best success rates included only motivated children and adolescents. It is well known that treatment adherence determines the success rate $(60,61)$.

Most importantly, adolescents with extreme obesity (BMI $\geq 35 \mathrm{~kg} / \mathrm{m}^{2}$ ), in contrast to those with Class I obesity (BMI $\left.30-35 \mathrm{~kg} / \mathrm{m}^{2}\right)$, did not reduce their BMI $(13,14)$. This 
suggests that lifestyle interventions are the treatment of choice for adolescents with non-severe (i.e. Class I) obesity. Bariatric surgery is not indicated in this group, and as such, has not been formally studied as it is currently felt that the effectiveness concerning cardiovascular risk factors may be similar to lifestyle interventions, and the risk of intervention-related complications and side effects does not appear warranted. As adolescents with severe obesity do not respond to lifestyle interventions, bariatric surgery should be a treatment option for this group. Accordingly, US, European and German guidelines suggest bariatric surgery should be considered only in adolescents with BMI $\geq 35 \mathrm{~kg} / \mathrm{m}^{2}(25,62,63,64)$.

These guidelines recommend that bariatric surgery should be considered only in adolescents with severe obesity who have participated in lifestyle interventions previously $(62,63,64)$. Furthermore, psychiatric diseases such as binge-eating disorders, emotional eating, drug abuse, schizophrenia, severe depression, suicidal tendency, severe borderline personality disorder, post-traumatic stress disorders, bulimia nervosa and other disorders have to be excluded or controlled within formal psychiatric treatment $(62,63)$. Psychiatric diseases are also considered exclusion criteria if, despite being treated, they prevent adherence to elements of the bariatric surgery pathway, such as nutritional supplementation, changing eating behavior, or reaching a balanced decision regarding obesity treatment. This diagnostic work-up is important as psychiatric diseases such as depression are common among adolescents with severe obesity, reported at $27 \%$ (23) to $39 \%$ (65). However, it is sometimes difficult in clinical practice to determine whether a psychiatric disease will benefit from the effective weight loss resulting from bariatric surgery (for example, major depression caused by extreme obesity) or whether the same psychiatric disease will cause difficulties in the long run with respect to treatment adherence.

We have analyzed the feasibility of these recommendations in our obesity department. Between the years 2012 and 2016, a total of 283 adolescents with severe obesity aged 14-18 years consulted our obesity treatment center with a BMI $\geq 35 \mathrm{~kg} / \mathrm{m}^{2}$ (mean BMI $41.4 \mathrm{~kg} / \mathrm{m}^{2}$; mean age 16.2 years, $55.5 \%$ male). All these adolescents with severe obesity were offered a standardized lifestyle intervention (66). However, only 76 (26.9\%) started and only 37 of these 76 adolescents (48.7\%) completed the lifestyle intervention. If the individuals desired bariatric surgery, they were offered a two-month manual-based pre-operative information program after participating in the lifestyle intervention. This was to ensure that the adolescents knew the potential risks and benefits of different bariatric surgery procedures. The content of this bariatric surgery preparation course has been published previously in a training manual (67). Ten (3.5\%) adolescents with severe obesity participated, and all of them completed this bariatric surgery preparation course. Two (20\%) of these ten adolescents with severe obesity refused bariatric surgery after the course. After the training course, an individual psychiatric examination was performed to exclude contraindications for bariatric surgery (such as binge-eating disorders, emotional eating, drug abuses, schizophrenia, severe depression, suicidal tendency, severe borderline personality, post-traumatic stress disorders or bulimia nervosa). The psychological examination was helpful to identify psychiatric conditions in two (20\%) adolescents, which represented contraindications for bariatric surgery $(58,59,60)$. Six (60\%) of the 10 adolescents fulfilled the three criteria: (a) completion of lifestyle intervention, (b) completion of bariatric surgery preparation course and (c) exclusion of somatic and psychiatric contraindications to bariatric surgery. Five of them underwent bariatric surgery, and in one case, health insurances denied financial imbursement. In summary, only six of 283 adolescents with severe obesity $(2.1 \%)$ presented in our institution wanted and were suitable for bariatric surgery according to guidelines $(25,58,59,60)$.

The main problem in our experience is that the great majority of adolescents with severe obesity get lost to follow-up. The low treatment adherence fits well with previous studies in adolescents with severe obesity (13, $14,15)$. Treatment adherence is a well-known problem in many chronic diseases such as obesity, especially in adolescents, and treatment outcome depends largely on adherence $(60,68,69)$. Adolescent patients often present greater challenges given the unique developmental, psychosocial and lifestyle issues implicit in adolescence $(60,70)$.

One could question whether it is meaningful to demand ineffective lifestyle intervention in adolescents with severe obesity before bariatric surgery. On the other hand, do we believe that adolescents with severe obesity who drop out of lifestyle interventions will visit the medical system after bariatric surgery and take their vitamin supplements regularly? This is of importance as vitamin and micronutrient supplementation is a requirement after bariatric surgery to avoid nutritional complications and side effects. Adolescent compliance with supplementation has been shown to be problematic after RYGB (27), and we do not have a reliable method of pre-operatively predicting likely compliance. 
Table 3 Eligibility for bariatric surgery.

$\frac{\text { BMI category }}{\geq 40 \mathrm{~kg} / \mathrm{m}^{2}}$

\begin{tabular}{l} 
Comorbid state \\
\hline Minor comorbidities
\end{tabular}

Example comorbidities

Body size precluding ambulation Dyslipidemia

Gastro-esophageal reflux disease Hypertension

Impaired activities of daily living

Impaired fasting glucose

Impaired glucose tolerance

Mild obstructive sleep apnea

Panniculitis

Severe psychosocial morbidity

Steatohepatitis

Urinary incontinence

Venous stasis

Weight-related joint disease

Benign intracranial hypertension

Heart failure due to obesity

Moderate-severe obstructive sleep apnea

Type 2 diabetes mellitus

$<35 \mathrm{~kg} / \mathrm{m}^{2} \quad$ Exceptional circumstances

Life-threatening obesity-related condition
As lifelong follow-up is necessary after bariatric surgery to monitor vitamin and micronutrient supplementation, effective transition models have to be developed involving general practitioners. Education should be provided to enable not only monitoring for potential nutritional complications but also to improve adherence to supplementation in the community.

One could argue that drugs for weight loss should be used before bariatric surgery. Using drugs would confer the advantage that treatment could be stopped in response to serious side effects. However, the only approved weight loss drug for adolescents (orlistat) has a moderate effect on weight, which is comparable to lifestyle interventions (71). The new drugs in the pipeline such as GLP-1 agonists, which are not approved for adolescents so far, have a greater effect on weight loss but the safety profile on the long run is not known yet (72). Several weight loss drugs, such as sibutramine and rimonabant, have been withdrawn from the market due to severe side effects, which have been recognized only after years of use.

Table 4 Exclusion criteria for bariatric surgery.

\begin{tabular}{lll}
\hline $\begin{array}{c}\text { Exclusion criteria } \\
\text { Patient and family }\end{array}$ & & Examples \\
understanding & & Inability to understand risks and benefits \\
Patient factors & $\begin{array}{l}\text { Inability to assent/consent as appropriate } \\
\text { Ongoing addiction (alcohol, drugs and } \\
\text { medication) } \\
\text { Skeletal immaturity (tanner stage } \leq \mathrm{III}) \\
\text { Treatable medical cause of obesity } \\
\text { Unstable psychiatric condition }\end{array}$ \\
\hline
\end{tabular}

Finally, drugs have to be taken lifelong, which presents the same difficulty with treatment adherence, particularly in adolescents, as supplementation after surgery.

\section{The case in support of bariatric surgery for adolescent obesity}

It is important to be clear that bariatric surgery is not a first-line therapy for adolescent obesity and is supported only when non-surgical treatments have been unsuccessful. Neither is bariatric surgery advocated in all adolescents with obesity; rather, it is reserved for those young people whose obesity is classified as severe, and whose health is already detrimentally affected by their obesity. In fact, existing eligibility criteria (Tables 3 and 4), as discussed in the above argument, restrict the use of bariatric surgery to a limited group of adolescents, in whom the benefits appear, thus far, to significantly outweigh the drawbacks.

As mentioned previously, weight loss is far greater within adolescent bariatric surgical programs than that in dietary and lifestyle programs, and we have long been armed with the knowledge that current dietary and lifestyle interventions for obesity generally fail to achieve positive long-term results (73). Dieting has been shown to be ineffective in the long term, both in adults and adolescents $(73,74,75,76)$. Worse than this, subjects often gain weight across study periods $(52,76$, 77). Typical weight loss in dietary and lifestyle programs for severe obesity equates to around $1-3 \mathrm{~kg} / \mathrm{m}^{2}(78,79)$, compared with $13.5 \mathrm{~kg} / \mathrm{m}^{2}$ after surgical procedures 
$(9,80)$. In addition, attrition rates are relatively high within dietary and lifestyle programs $(43,81,82)$ and, even when these therapies are successful, many individuals' obesity will not resolve as the few $\mathrm{kg} / \mathrm{m}^{2}$ lost represent a small fraction of their overall BMI (83).

The adult bariatric literature demonstrates marked cardiovascular benefits after bariatric surgery. Cardiovascular risk factors improve after surgery: the risk of hypertension almost halves, the risk of dyslipidemia and type 2 diabetes mellitus (T2DM) reduces by twothirds and inflammation is markedly reduced (84). This amelioration of cardiovascular risk leads to reduction in the risk of myocardial infarction, stroke and death, each by around $50 \%$ in adults (84). As a relatively new field of study, and as participants are young, there will be a substantial lag before the literature describing such outcomes in adolescents reaches maturity.

T2DM is a debilitating and progressive disease, which was almost unheard of in children before the turn of this century (85). Its prevalence in adolescents is rapidly rising, in parallel with a rising prevalence of obesity (86) and is likely underestimated by up to $50 \%(87,88)$. Alarming evidence suggests that T2DM behaves far more aggressively when onset is in adolescence, with earlier failure of first-line drug pharmacotherapy and more rapid progression to insulin requirement $(9,89)$. A broad evidence base, comprising eleven randomized trials, now describes bariatric surgery as an effective therapy for T2DM in adults, leading not only to the glycemic control seen with pharmacotherapy but also to remission of diabetes in $33-90 \%$ of patients (90). No other therapy, including weight loss by other methods, has reliably achieved this endpoint, sparking the recent development of guidelines to help physicians appropriately utilize surgery as an effective treatment for T2DM and obesity (91). Similar adolescent trials are lacking thus far and are desperately needed (92), but existing studies have shown T2DM resolution in $79-100 \%$ cases after RYGB $(22,93)$, $50-94 \%$ after LSG (80) and 100\% after LAGB (80).

Suggestions to delay surgical treatment for T2DM present a significant cause for concern when we consider evidence that delayed treatment in adults is far less likely to achieve remission, let alone lasting remission. Sjöstrom and coworkers (94) showed, in the Swedish Obese Subjects study, that when T2DM diagnosis was new ( $<1$ year), bariatric surgery resulted in $>90 \%$ remission, whereas established (diagnosed for $>4$ years) T2DM remitted in $<40 \%$ of patients. Furthermore, remission at 15 years was almost $50 \%$ in the newly diagnosed group, compared with $<10 \%$ in the established diagnosis group.
Furthermore, delaying surgical treatment influences not only the T2DM remission rate but also the outcome in respect to weight status. As Inge and coworkers have previously shown (95), the trough of BMI loss after RYGB is around 37\% regardless of baseline BMI. Again, this raises the question of whether bariatric surgery should be offered before extreme BMI values (e.g. $>45 \mathrm{~kg} / \mathrm{m}^{2}$ ) are reached.

Many of the concerns identified in the case against adolescent bariatric surgery relate to side effects, both known and unknown. A significant and growing body of research has demonstrated that side effects are generally limited and well tolerated $(16,18,26,27)$. While considering side effects of surgery, it is noteworthy that adverse events occurred in $44 \%$ of patients treated nonsurgically in the only existing randomized trial of bariatric surgery (21).

The three main bariatric procedures used in adults today have also been used in adolescents (80). However, the laparoscopic adjustable gastric band is not licensed for use in adolescents in the United States, and its use in adolescents is not widely supported, partly owing to high rates of reoperation for complications (64). Current evidence has demonstrated outcomes after laparoscopic sleeve gastrectomy (LSG) and RYGB to be similar to those in adults, leading to support for their use in adolescents (96). LSG is supported by a younger evidence base in comparison to the RYGB and is generally considered investigational. The most commonly used procedure to date is the RYGB, and guidance supports its use in adolescents $(64,97)$.

All surgical procedures should be expected to have, and respected as having, an associated mortality; it is simply a question of how many procedures one would need to perform to prove as much. Indeed, although the mortality of adolescent bariatric surgery is above zero (28), lethal complications of severe childhood obesity itself also exist (98) and increase with rising BMI (99). Therefore, it could be argued that the mortality of non-surgical interventions is, therefore, also above zero. Thankfully, the field of adult bariatric surgery has developed an impressive safety record, based upon significant advances in surgical technique, anesthetic practices, selection criteria and specialist multidisciplinary management of patients. This has led to a $97-99 \%$ reduction in the mortality of adult bariatric surgery from $8 \%(100)$ to $0.08-0.22 \%$ (101) across roughly 50 years, in a population generally presenting with existing comorbidities. Thus far, the occurrence of death within 30 days of adult bariatric surgery in RYGB is now comparable to that of an elective laparoscopic 
cholecystectomy $(102,103)$, often performed solely for symptomatic benefit. All three reported deaths beyond 30 days after adolescent bariatric surgery were reported to be unrelated to the operation. One patient died over three years after surgery from hypoglycemia as a result of type 1 diabetes mellitus (22), and the remaining two also demonstrated significant pre-operative comorbidity, despite their youth, and died two and six years after surgery respectively, their exact causes of death unspecified (55).

It was previously hypothesized that problematic excess skin would be encountered less frequently after adolescent bariatric surgery as skin may retain elasticity and more readily normalize (104). However, data have shown that the requirement for plastic surgery is similar in adolescents as that in adults after bariatric surgery (104).

The dumping syndrome is often quoted, as mentioned previously, to be a major drawback of RYGB surgery $(30,32)$. In our unit, we have shown that most patients, including adolescents, do not experience any symptoms of dumping after RYGB (31), although the prevalence has been reported elsewhere at over 75\% (105). The implication of this collection of symptoms takes on a very different meaning when we talk to patients. Of those experiencing symptoms, most actually find that the discomfort that follows consumption of high-calorie or high-sugar foods offers a powerful and desirable feedback mechanism to help avoidance of unfavorable, or 'naughty', eating habits (106). Of course, a small number of patients perceive their dumping as a significant burden, and one in ten patients experiences troublesome symptoms (105).

Concerns about potential growth retardation after bariatric surgery have not been founded upon any evidence to date. On the contrary, there is evidence that young people, whether prepubertal, adolescent or in young adulthood, experience normal growth velocity after sleeve gastrectomy (18). Compared with matched non-surgically treated controls, aged younger than 14 years increased in height by over $10 \mathrm{~mm}$ /year more after LSG, equating to over $5 \mathrm{~cm}$ more across four years of follow-up (107). Such evidence is limited because patient selection criteria (64) for the most common procedure, RYGB, stipulate that candidates should generally have reached at least Tanner stage IV $(108,109)$ and $95 \%$ of estimated growth. Therefore, by definition, there is little outstanding growth to be affected in the majority of patients eligible for bariatric surgery in adolescence.

Similarly, concerns surrounding bone health in adolescents after bariatric surgery have not been proven. Evidence is currently limited to two-year follow-up, but shows that bone mineral content and density fall from abnormally high-for-age pre-operative levels to normalfor-age levels after surgery $(110,111)$. Long-term effects on the skeleton have not yet been reported, but must be examined, including long-term vitamin $\mathrm{D}$ and calcium absorption. When considering post-operative vitamin D deficiency, we must bear in mind that deficiency is widespread, with prevalence in a variety of young healthy populations of around $30-50 \%$ (112), including $42 \%$ in healthy adolescents (113).

Similar to vitamin D, other vitamin and nutrient deficiencies are well recognized in the short and long term after adult bariatric surgery (114). As a result, it is imperative that long-term formal monitoring is in place to identify and manage abnormalities. The suggestion that surgery should be postponed until adulthood in eligible adolescents is reached does not appear evidence based as rates of significant nutritional abnormalities generally appear comparable between adolescent and adult groups after bariatric surgery (Table 1). Note that although post-operative hypoferritinemia has been reported to be common in adolescents (22), iron stores actually increase after bariatric surgery in adolescents (27), suggesting the reversal of chronic inflammatory processes may be contributory to falling ferritin levels (115).

Refeeding syndrome, as described in the case against, is a potentially devastating complication of bariatric surgery. However, this is an exceptionally rare occurrence, with no cases reported in adolescents and only a single case reported in an adult following the extreme malabsorptive procedure, biliopancreatic diversion (34), which is not recommended in adolescents (64). Other serious consequences include beriberi or vitamin B1 (thiamine) deficiency. Beriberi is also rare and, with prompt recognition and thiamine supplementation, complete resolution can be achieved (116). These cases highlight the importance of effective follow-up to minimize the occurrence and impact of nutritional deficiencies.

Eating behavior does indeed change after bariatric surgery, with migration toward small portions after bariatric surgery (117). However, this reduction in portion sizes, observed following LSG and RYGB, is not brought about by a change in the patient's will power or commitment, nor does it appear to be predominantly a result of restriction of nutrient intake and passage through the gut. Rather, it is the hormonal effects of the procedures that lead to reduced hunger and earlier satiety, resulting in a tendency to eat smaller volumes and less frequently (117).

Gastrointestinal reflux is more common in obesity than normal weight (101). When present, significant 
reflux will usually affect the surgeon's procedure recommendation as reflux symptoms significantly improve after RYGB, whereas the effects of LSG and LAGB on reflux are not conclusively understood $(118,119$, 120). There is no evidence of a greater risk of dysplasia or neoplasia of the esophagus after bariatric surgery, and a recent systematic review reported only 11 cases reaching back as far as 1996 (121). Epidemiological data have shown that obesity is associated with an increased risk of esophageal cancer (122), along with cancers of the thyroid, colorectum, breast, endometrium, cervix, ovary, kidney, stomach, liver, gallbladder and pancreas $(122,123)$. Reversal of obesity using bariatric surgery in adolescence thereby actually reduces the duration and degree of exposure to this significant risk factor for a broad range of cancers. This has been demonstrated to translate to a one-third reduction in overall cancer risk among women across a median ten-year follow-up (124). Further than this, Christou and coworkers (125) observed that patients were $80 \%$ less likely to receive a diagnosis of cancer within five years of bariatric surgery than nonsurgical controls and Adams and coworkers (126) reported $60 \%$ fewer deaths from cancer, and $40 \%$ fewer deaths from all causes, after a mean of seven years.

Patients whose obesity is related to specific genetic mutations, such as MC4R, or syndromes, such as PraderWilli, represent a tiny minority of adolescents undergoing bariatric surgery, strictly as exceptions to recommended exclusion criteria (9). Reported outcomes in these patients have varied widely, but are often inferior to those in 'normal' adolescent obesity $(127,128,129)$. The benefits and risks of surgery in these groups should be considered quite separately to those of the general adolescent population with obesity as the mechanisms of their obesity are different.

Obesity in adolescence is associated with significant and highly prevalent psychosocial impairment (130). The presence of an untreated psychiatric condition is a contraindication to bariatric surgery but, if appropriately controlled with treatment, mental health disorders do not preclude eligibility (64). Within the AMOS (27) and Teen-LABS (22) studies, rates of psychosocial impairment among adolescents undergoing surgery for severe obesity were as high as $68 \%$ (27), with depressive symptoms in $27 \%$ (23) to $39 \%$ (65). The fact that a small proportion of patients experienced psychosocial deterioration emphasizes the extreme vulnerability of this population. In the only existing non-surgical 10-year follow-up study, almost $10 \%$ of participants were hospitalized with psychiatric problems, two (3\%) attempting suicide (50).
However, although bariatric procedures are not designed to improve psychosocial function, psychosocial outcomes after bariatric surgery have been grossly positive, with significant reduction of symptoms of anxiety, depression and anger, alongside improvements in self-esteem, selfconcept and overall mood $(65,111)$. The exploration of methods for identifying those at greatest risk of postoperative psychosocial impairment should be a major focus in this field to ensure additional support is directed to these individuals.

The case against describes encountering major hurdles in enrolling patients into a bariatric surgical program as many dropped out of preceding lifestyle interventions. Rates of compliance with lifestyle programs prior to enrolment into bariatric surgical programs are not reported among the major surgical series, although recruitment difficulties were not highlighted as problematic (26, 131). Furthermore, in Sweden, almost one in every 1000 citizens undergoes bariatric surgery each year, a rate twice as high as that of the US (132). Public understanding and acceptance of bariatric surgery is high in Sweden as a result, perhaps more so than in many other countries. This may contribute to a greater acceptance of adolescent bariatric surgery as a viable therapeutic option, and perhaps goes some way to explaining the local difficulty described in Germany within the case against, where surgery is almost ten times less common (132). However, other nations with roughly half the rate of bariatric surgery of Sweden, such as the United States and Saudi Arabia, have recruited sizable adolescent series $(22,107)$.

The case against accurately alludes to the wealth of randomized trials evaluating the effects of lifestyle interventions and concluding their superiority to standard care or self-help at 6 and 12 months. It is also acknowledged that, within the mature literature base, comprising more than 70 randomized trials and at least seven metaanalyses in the past decade, reports of outcomes of nonsurgical interventions beyond 12-24 months are rare $(43,44,82,133,134,135,136,137)$. This is suggestive of significant publication bias toward short-term reports. The efficacy of such interventions in terms BMI/weight measures, although often significant, is consistently modest at best. Of the few studies reporting outcomes at five years or more, only one followed up more than 100 patients (51). Furthermore, very few studies have focused on severe obesity (83), and adolescents with severe obesity in these programs are more likely to fail to lose weight or regain weight within two to three years $(13,14,46)$.

It has been proven possible to achieve good rates of follow-up (>75\%) to two or more years in adolescent 
bariatric surgical programs $(22,86)$. However, follow-up does present a major challenge, particularly in relation to individuals whose outcome is favorable and who no longer feel reliant upon health services. Reliable follow-up strategies are sorely needed across all interventions for obesity. Technological solutions may play a part in this.

Compliance with the necessary multiple daily supplements is another such issue, as adolescents are disinclined to take prescribed medication after bariatric surgery (27). However, the advent of compounds, containing all standard supplements in a single tablet, may increase the palatability of supplements to adolescents (138).

Despite the immaturity of the literature base describing bariatric surgical outcomes in adolescents with severe obesity, with robust five-year outcomes imminently emerging from Europe (139) and the United States (140), it is rapidly catching up with the long-term evidence on non-surgical interventions.

In the context of marked limitations in the effectiveness of non-surgical approaches to adolescent severe obesity, further research into bariatric surgery is of extreme urgency and importance. More important than specifically identifying those who benefit most from surgery, we must focus resources on identifying those who experience difficulty or suboptimal outcomes after surgery to ensure they are fully supported, to find solutions to their difficulties and to optimize outcomes in future candidates.

\section{Conclusions}

The authors of the case for and the case against bariatric surgery in adolescents are in agreement that bariatric surgery offers superior therapeutic outcomes, in terms of weight loss and resolution of comorbid disease states, over other existing treatments for severe obesity in adolescence. However, we also agree regarding a number of important considerations within adolescent bariatric surgery.

Firstly, the evidence currently underpinning surgical treatments is from studies of adolescents whose obesity is severe and whose growth is near complete. As such, we cannot currently recommend consideration of bariatric surgery for non-severe obesity (BMI $<35 \mathrm{~kg} / \mathrm{m}^{2}$ ) or the very young, except under the exceptional circumstances of life-threatening obesity-related conditions. When BMI is $<35 \mathrm{~kg} / \mathrm{m}^{2}$, less invasive treatments, which are proven to offer significant benefit, should be considered instead.
Second, the effect of lifestyle interventions and/or medications is only moderate in adolescents with severe obesity (BMI $\geq 35 \mathrm{~kg} / \mathrm{m}^{2}$ ), and these patients should be offered bariatric surgery. This should be exclusively within formal programs, delivered by specialist multidisciplinary child/adolescent obesity teams, within specialist centers. Patients and their family/careers must be educated regarding the benefits and risks, including the irreversibility of the procedure where applicable, potential side effects, expected changes in eating behavior and the lifelong requirement for regular medical follow-up after surgery. In cases of syndromes, genetic mutations or injury affecting satiety regulation, bariatric surgery should be discussed by the multidisciplinary team on an individual-case basis to assess the potential for deterioration in quality of life after surgery. Before initiating bariatric surgery in adolescents with severe obesity, compliance to treatment should be demonstrated to minimize the risk of nutritional deficiencies and associated potential complications.

Third, as an emerging research field, the follow-up evidence in the adolescent population largely refers to short- and medium-term outcomes at present. Robust long-term evidence, although emerging, is currently limited. Such evidence will be crucial to answer questions and concerns regarding the long-term effects, both positive and negative, of bariatric surgery, as treated adolescents progress into adulthood. Similarly, although the risks of non-surgical interventions appear fewer in the short term, their long-term effectiveness also requires formal evaluation.

Finally, as invasive and often irreversible procedures, with varying outcomes for individuals, conscious efforts must be made to identify factors associated with successful and suboptimal outcomes, both physical and psychological, optimizing patient selection criteria and outcomes.

Therefore, when other treatments for adolescent severe obesity are unsuccessful, it is appropriate to consider the use of bariatric surgery, within the context of existing guidance.

\section{Declaration of interest}

The authors declare that there is no conflict of interest that could be perceived as prejudicing the impartiality of the research reported.

\section{Funding}

Andrew Beamish was the recipient of the 'David Johnston' Bariatric Research Fellowship from the Royal College of Surgeons of England 
and was also funded by Department of Gastrosurgical Research, Institute of Clinical Sciences, Gothenburg University, Sweden. Thomas Reinehr was funded by the Federal Ministry of Education and Research (BMBF, 01GI1120A, 01GI1120B), which is included in the competence network obesity.

\section{References}

1 Ng M, Fleming T, Robinson M, Thomson B, Graetz N, Margono C, Mullany EC, Biryukov S, Abbafati C, Abera SF et al. Global, regional, and national prevalence of overweight and obesity in children and adults during 1980-2013: a systematic analysis for the Global Burden of Disease Study 2013. Lancet 2014384 766-781. (doi:10.1016/S0140-6736(14)60460-8)

2 Ells LJ, Hancock C, Copley VR, Mead E, Dinsdale H, Kinra S, Viner RM \& Rutter H. Prevalence of severe childhood obesity in England: 2006-2013. Archives of Disease in Childhood 2015100 631-636. (doi:10.1136/archdischild-2014-307036)

3 van Jaarsveld $\mathrm{CH} \&$ Gulliford MC. Childhood obesity trends from primary care electronic health records in England between 1994 and 2013: population-based cohort study. Archives of Disease in Childhood 2015100 214-219. (doi:10.1136/ archdischild-2014-307151)

4 van Dommelen P, Schonbeck Y, van Buuren S \& HiraSing RA. Trends in a life threatening condition: morbid obesity in dutch, Turkish and Moroccan children in The Netherlands. PLOS ONE 20149 e94299. (doi:10.1371/journal.pone.0094299)

5 I'Allemand D, Wiegand S, Reinehr T, Muller J, Wabitsch M, Widhalm K, Holl R \& Group AP-S. Cardiovascular risk in 26,008 European overweight children as established by a multicenter database. Obesity 200816 1672-1679. (doi:10.1038/oby.2008.259)

6 Beamish AJ \& Olbers T. Bariatric and metabolic surgery in adolescents: a path to decrease adult cardiovascular mortality. Current Atherosclerosis Reports 201517 53. (doi:10.1007/s11883015-0532-7)

7 Michalsky MP, Inge TH, Simmons M, Jenkins TM, Buncher R, Helmrath M, Brandt ML, Harmon CM, Courcoulas A, Chen $\mathrm{M}$ et al. Cardiovascular risk factors in severely obese adolescents: the teen longitudinal assessment of bariatric surgery (Teen-LABS) study. JAMA Pediatrics $2015169438-444$. (doi:10.1001/jamapediatrics.2014.3690)

8 Shah AS, Dolan LM, Khoury PR, Gao Z, Kimball TR \& Urbina EM. Severe obesity in adolescents and young adults is associated with subclinical cardiac and vascular changes. Journal of Clinical Endocrinology and Metabolism 2015100 2751-2757. (doi:10.1210/ jc.2014-4562)

9 Beamish AJ, Johansson SE \& Olbers T. Bariatric surgery in adolescents: what do we know so far? Scandinavian Journal of Surgery 2015104 24-32. (doi:10.1177/1457496914553150)

10 Magallares A \& Schomerus G. Mental and physical health-related quality of life in obese patients before and after bariatric surgery: a meta-analysis. Psychology Health and Medicine 201520 165-176. (doi:10.1080/13548506.2014.963627)

11 Zeller MH, Inge TH, Modi AC, Jenkins TM, Michalsky MP, Helmrath M, Courcoulas A, Harmon CM, Rofey D, Baughcum A et al. Severe obesity and comorbid condition impact on the weight-related quality of life of the adolescent patient. Journal of Pediatrics 2015166 651-659.e654. (doi:10.1016/j. jpeds.2014.11.022)

12 Zeller MH, Roehrig HR, Modi AC, Daniels SR \& Inge TH. Healthrelated quality of life and depressive symptoms in adolescents with extreme obesity presenting for bariatric surgery. Pediatrics 2006117 1155-1161. (doi:10.1542/peds.2005-1141)

13 Danielsson P, Kowalski J, Ekblom O \& Marcus C. Response of severely obese children and adolescents to behavioral treatment.
Archives of Pediatrics and Adolescent Medicine 2012166 1103-1108. (doi:10.1001/2013.jamapediatrics.319)

14 Knop C, Singer V, Uysal Y, Schaefer A, Wolters B \& Reinehr T. Extremely obese children respond better than extremely obese adolescents to lifestyle interventions. Pediatric Obesity 201510 7-14. (doi:10.1111/j.2047-6310.2013.00212.x)

15 Muhlig Y, Wabitsch M, Moss A \& Hebebrand J. Weight loss in children and adolescents. Deutsches Ärzteblatt International 2014 111 818-824.

16 Lennerz BS, Wabitsch M, Lippert H, Wolff S, Knoll C, Weiner R, Manger T, Kiess W \& Stroh C. Bariatric surgery in adolescents and young adults-safety and effectiveness in a cohort of 345 patients. International Journal of Obesity 201438 334-340. (doi:10.1038/ ijo.2013.182)

17 Kelleher DC, Merrill CT, Cottrell LT, Nadler EP \& Burd RS. Recent national trends in the use of adolescent inpatient bariatric surgery: 2000 through 2009. JAMA Pediatrics 2013167 126-132. (doi:10.1001/2013.jamapediatrics.286)

18 Alqahtani AR, Elahmedi MO \& Al Qahtani A. Co-morbidity resolution in morbidly obese children and adolescents undergoing sleeve gastrectomy. Surgery for Obesity and Related Diseases 201410 842-850. (doi:10.1016/j.soard.2014.01.020)

19 Black JA, White B, Viner RM \& Simmons RK. Bariatric surgery for obese children and adolescents: a systematic review and meta-analysis. Obesity Reviews 201314 634-644. (doi:10.1111/ obr.12037)

20 Ells LJ, Mead E, Atkinson G, Corpeleijn E, Roberts K, Viner R, Baur L, Metzendorf MI \& Richter B. Surgery for the treatment of obesity in children and adolescents. Cochrane Database Systematic Reviews 20156 CD011740.

21 O'Brien PE, Sawyer SM, Laurie C, Brown WA, Skinner S, Veit F, Paul E, Burton PR, McGrice M, Anderson M et al. Laparoscopic adjustable gastric banding in severely obese adolescents: a randomized trial. JAMA 2010303 519-526. (doi:10.1001/ jama.2010.81)

22 Inge $\mathrm{TH}$, Courcoulas $\mathrm{AP}$, Jenkins TM, Michalsky MP, Helmrath MA, Brandt ML, Harmon CM, Zeller MH, Chen MK, Xanthakos SA et al. Weight loss and health status 3 years after bariatric surgery in adolescents. New England Journal of Medicine 2016374 113-123. (doi:10.1056/NEJMoa1506699)

23 Jarvholm K, Olbers T, Marcus C, Marild S, Gronowitz E, Friberg P, Johnsson P \& Flodmark CE. Short-term psychological outcomes in severely obese adolescents after bariatric surgery. Obesity 2012 20 318-323. (doi:10.1038/oby.2011.310)

24 Dawes AJ, Maggard-Gibbons M, Maher AR, Booth MJ, Miake-Lye I, Beroes JM \& Shekelle PG. Mental health conditions among patients seeking and undergoing bariatric surgery: a meta-analysis. JAMA 2016315 150-163. (doi:10.1001/ jama.2015.18118)

25 Inge TH, Krebs NF, Garcia VF, Skelton JA, Guice KS, Strauss RS, Albanese CT, Brandt ML, Hammer LD, Harmon CM et al. Bariatric surgery for severely overweight adolescents: concerns and recommendations. Pediatrics 2004114 217-223. (doi:10.1542/ peds.114.1.217)

26 Inge $\mathrm{TH}$, Zeller $\mathrm{MH}$, Jenkins TM, Helmrath $\mathrm{M}$, Brandt ML, Michalsky MP, Harmon CM, Courcoulas A, Horlick M, Xanthakos SA et al. Perioperative outcomes of adolescents undergoing bariatric surgery: the Teen-Longitudinal Assessment of Bariatric Surgery (Teen-LABS) study. JAMA Pediatrics 2014168 47-53. (doi:10.1001/jamapediatrics.2013.4296)

27 Olbers T, Gronowitz E, Werling M, Marlid S, Flodmark CE, Peltonen M, Gothberg G, Karlsson J, Ekbom K, Sjostrom LV et al. Two-year outcome of laparoscopic Roux-en-Y gastric bypass in adolescents with severe obesity: results from a Swedish Nationwide Study (AMOS). International Journal of Obesity 201236 1388-1395. (doi:10.1038/ijo.2012.160) 
28 Michalsky M, Teich S, Rana A, Teeple E, Cook S \& Schuster D. Surgical risks and lessons learned: mortality following gastric bypass in a severely obese adolescent. Journal of Pediatric Surgery Case Reports 20131 321-324. (doi:10.1016/j.epsc.2013.08.013)

29 Banerjee A, Ding Y, Mikami DJ \& Needleman BJ. The role of dumping syndrome in weight loss after gastric bypass surgery. Surgical Endoscopy 201327 1573-1578. (doi:10.1007/s00464-0122629-1)

30 Calabria AC, Gallagher PR, Simmons R, Blinman T \& De Leon DD. Postoperative surveillance and detection of postprandial hypoglycemia after fundoplasty in children. Journal of Pediatrics 2011159 597-601.e591. (doi:10.1016/j.jpeds.2011.03.049)

31 Laurenius A, Olbers T, Naslund I \& Karlsson J. Dumping syndrome following gastric bypass: validation of the dumping symptom rating scale. Obesity Surgery 201323 740-755. (doi:10.1007/s11695-012-0856-0)

32 Barnett SJ, Stanley C, Hanlon M, Acton R, Saltzman DA, Ikramuddin S \& Buchwald H. Long-term follow-up and the role of surgery in adolescents with morbid obesity. Surgery for Obesity and Related Diseases 20051 394-398. (doi:10.1016/j. soard.2005.03.206)

33 Becker DA, Balcer LJ \& Galetta SL. The neurological complications of nutritional deficiency following bariatric surgery. Journal of Obesity 20122012 608534. (doi:10.1155/2012/608534)

34 Chiappetta S \& Stein J. Refeeding syndrome: an important complication following obesity surgery. Obesity Facts 20169 12-16. (doi:10.1159/000442534)

35 Mehanna HM, Moledina J \& Travis J. Refeeding syndrome: what it is, and how to prevent and treat it. BMJ 2008336 1495-1498. (doi:10.1136/bmj.a301)

36 Borovicka J, Krieger-Grubel C, van der Weg B, Thurnheer M, Schultes B, Sulz MC, Gutzwiler JP, Bisang P, Pohl D, Fried M et al. Effect of morbid obesity, gastric banding and gastric bypass on esophageal symptoms, mucosa and function. Surgical Endoscopy 2016. Epub ahead of print. (doi:10.1007/s00464-016-4996-5)

37 Melstrom LG, Bentrem DJ, Salvino MJ, Blum MG, Talamonti MS \& Printen KJ. Adenocarcinoma of the gastroesophageal junction after bariatric surgery. American Journal of Surgery 2008196 135-138. (doi:10.1016/j.amjsurg.2007.07.026)

38 Cushing CC, Peugh JL, Brode CS, Inge TH, Benoit SC \& Zeller MH. Longitudinal trends in food cravings following Roux-en-Y gastric bypass in an adolescent sample. Surgery for Obesity and Related Diseases 201511 14-18. (doi:10.1016/j.soard.2014.05.035)

39 Jarvholm K, Karlsson J, Olbers T, Peltonen M, Marcus C, Dahlgren J, Gronowitz E, Johnsson P \& Flodmark CE. Twoyear trends in psychological outcomes after gastric bypass in adolescents with severe obesity. Obesity 201523 1966-1972. (doi:10.1002/oby.21188)

40 Bhatti UH, Duffy AJ, Roberts KE \& Shariff AH. Nephrolithiasis after bariatric surgery: A review of pathophysiologic mechanisms and procedural risk. International Journal of Surgery 201636 618-623. (doi:10.1016/j.ijsu.2016.11.025)

41 Nehus EJ, Khoury JC, Inge TH, Xiao N, Jenkins TM, MoxeyMims MM \& Mitsnefes MM. Kidney outcomes three years after bariatric surgery in severely obese adolescents. Kidney International 2016.

42 Reinehr T. Lifestyle intervention in childhood obesity: changes and challenges. Nature Reviews Endocrinology 20139 607-614. (doi:10.1038/nrendo.2013.149)

43 McGovern L, Johnson JN, Paulo R, Hettinger A, Singhal V, Kamath C, Erwin PJ \& Montori VM. Clinical review: treatment of pediatric obesity: a systematic review and meta-analysis of randomized trials. Journal of Clinical Endocrinology and Metabolism 200893 4600-4605. (doi:10.1210/jc.2006-2409)

44 Oude Luttikhuis H, Baur L, Jansen H, Shrewsbury VA, O'Malley C, Stolk RP \& Summerbell CD. Interventions for treating obesity in children. Cochrane Database of Systematic Reviews 2009 CD001872. (doi:10.1002/14651858.CD001872.pub2)

45 Katz DL, O'Connell M, Njike VY, Yeh MC \& Nawaz H. Strategies for the prevention and control of obesity in the school setting: systematic review and meta-analysis. International Journal of Obesity 200832 1780-1789. (doi:10.1038/ijo.2008.158)

46 Savoye M, Nowicka P, Shaw M, Yu S, Dziura J, Chavent G, O'Malley G, Serrecchia JB, Tamborlane WV \& Caprio S. Long-term results of an obesity program in an ethnically diverse pediatric population. Pediatrics 2011127 402-410. (doi:10.1542/peds.2010-0697)

47 Reinehr T, Hoffmeister U, Mann R, Goldapp C, Westenhofer J, Egmond-Froehlich A, Bullinger M, Ravens-Sieberer U \& Holl RW. Medical care of overweight children under real-life conditions: the German BZgA observation study. International Journal of Obesity 200933 418-423. (doi:10.1038/ijo.2009.50)

48 Reinehr T, Widhalm K, l'Allemand D, Wiegand S, Wabitsch M, Holl RW, APV-Wiss STudy Group \& German Competence Net Obesity. Two-year follow-up in 21,784 overweight children and adolescents with lifestyle intervention. Obesity 200917 1196-1199. (doi:10.1038/oby.2009.17)

49 Vignolo M, Rossi F, Bardazza G, Pistorio A, Parodi A, Spigno S, Torrisi C, Gremmo M, Veneselli E \& Aicardi G. Five-year follow-up of a cognitive-behavioural lifestyle multidisciplinary programme for childhood obesity outpatient treatment. European Journal of Clinical Nutrition 200862 1047-1057. (doi:10.1038/ sj.ejcn.1602819)

50 Epstein LH, Valoski A, Wing RR \& McCurley J. Ten-year follow-up of behavioral, family-based treatment for obese children. JAMA 1990264 2519-2523. (doi:10.1001/ jama.1990.03450190051027)

51 Reinehr T, Kleber M, Lass N \& Toschke AM. Body mass index patterns over $5 \mathrm{y}$ in obese children motivated to participate in a 1-y lifestyle intervention: age as a predictor of long-term success. American Journal of Clinical Nutrition 201091 1165-1171. (doi:10.3945/ajcn.2009.28705)

52 Ho M, Garnett SP, Baur L, Burrows T, Stewart L, Neve M \& Collins C. Effectiveness of lifestyle interventions in child obesity: systematic review with meta-analysis. Pediatrics 2012130 e1647-e1671. (doi:10.1542/peds.2012-1176)

53 Reinehr T, Kleber M \& Toschke AM. Lifestyle intervention in obese children is associated with a decrease of the metabolic syndrome prevalence. Atherosclerosis 2009207 174-180. (doi:10.1016/j.atherosclerosis.2009.03.041)

54 Lass N, Kleber M, Winkel K, Wunsch R \& Reinehr T. Effect of lifestyle intervention on features of polycystic ovarian syndrome, metabolic syndrome, and intima-media thickness in obese adolescent girls. Journal of Clinical Endocrinology and Metabolism 201196 3533-3540. (doi:10.1210/jc.2011-1609)

55 Sugerman HJ, Sugerman EL, DeMaria EJ, Kellum JM, Kennedy C, Mowery Y \& Wolfe LG. Bariatric surgery for severely obese adolescents. Journal of Gastrointestinal Surgery 20037 102-107; discussion 107-108. (doi:10.1016/S1091-255X(02)00125-7)

56 Wille N, Bullinger M, Holl R, Hoffmeister U, Mann R, Goldapp C, Reinehr T, Westenhofer J, Egmond-Froehlich A \& Ravens-Sieberer U. Health-related quality of life in overweight and obese youths: results of a multicenter study. Health and Quality of Life Outcomes 20108 36. (doi:10.1186/1477-7525-8-36)

57 Finne E, Reinehr T, Schaefer A, Winkel K \& Kolip P. Changes in self-reported and parent-reported health-related quality of life in overweight children and adolescents participating in an outpatient training: findings from a 12-month follow-up study. Health and Quality of Life Outcomes 201311 1. (doi:10.1186/14777525-11-1)

58 Anderson JW, Konz EC, Frederich RC \& Wood CL. Long-term weight-loss maintenance: a meta-analysis of US studies. American Journal of Clinical Nutrition $2001 \mathbf{7 4} 579-584$. 
59 Finne E, Reinehr T, Schaefer A, Winkel K \& Kolip P. Overweight children and adolescents-is there a subjective need for treatment? International Journal of Public Health 200954 112-116. (doi:10.1007/s00038-009-8004-x)

60 Osterberg L \& Blaschke T. Adherence to medication. New England Journal of Medicine 2005353 487-497. (doi:10.1056/ NEJMra050100)

61 Denzer C, Reithofer E, Wabitsch M \& Widhalm K. The outcome of childhood obesity management depends highly upon patient compliance. European Journal of Pediatrics 2004163 99-104. (doi:10.1007/s00431-003-1376-7)

62 Guidelines of the German working group on obese children and adolescents, 2016.

63 Fried M, Hainer V, Basdevant A, Buchwald H, Deitel M, Finer N, Greve JW, Horber F, Mathus-Vliegen E, Scopinaro N et al. Interdisciplinary European guidelines on surgery of severe obesity. International Journal of Obesity 200731 569-577. (doi:10.1038/ sj.ijo.0803560)

64 Pratt JS, Lenders CM, Dionne EA, Hoppin AG, Hsu GL, Inge TH, Lawlor DF, Marino MF, Meyers AF, Rosenblum JL et al. Best practice updates for pediatric/adolescent weight loss surgery. Obesity 200917 901-910. (doi:10.1038/oby.2008.577)

65 Zeller MH, Modi AC, Noll JG, Long JD \& Inge TH. Psychosocial functioning improves following adolescent bariatric surgery. Obesity 200917 985-990. (doi:10.1038/oby.2008.644)

66 Wabitsch M, Moss A, Reinehr T, Wiegand S, Kiess W, Scherag A, Holl R, Holle R \& Hebebrand J. Medical and psychosocial implications of adolescent extreme obesity - acceptance and effects of structured care, short: Youth with Extreme Obesity Study (YES). BMC Public Health 201313 789. (doi:10.1186/14712458-13-789)

67 Lennerz B, Wabitsch M, Geisler A, Hebebrand J, Kiess W, Moss A, Mühlig Y, Singer V, Uysal Y, Wiegand S \& Reinehr T. Manual-basiertes Vorgehen zur Vorbereitung und Nachsorge von bariatrisch-chirurgischen Eingriffen bei Jugendlichen. Adipositas $201411-7$.

68 Rausch JR, Hood KK, Delamater A, Shroff Pendley J, Rohan JM, Reeves G, Dolan L \& Drotar D. Changes in treatment adherence and glycemic control during the transition to adolescence in type 1 diabetes. Diabetes Care 201235 1219-1224. (doi:10.2337/dc112163)

69 Lass N \& Reinehr T. Low treatment adherence in pubertal children treated with thyroxin or growth hormone. Hormone Research in Paediatrics 201584 240-247. (doi:10.1159/000437305)

70 Friedman IM \& Litt IF. Adolescents' compliance with therapeutic regimens. Psychological and social aspects and intervention. Journal of Adolescent Health Care 19878 52-67. (doi:10.1016/01970070(87)90246-4)

71 Chanoine J-P \& Richard M. Early weight loss and outcome at one year in obese adolescents treated with orlistat or placebo. International Journal of Pediatric Obesity 20116 95-101. (doi:10.310 9/17477166.2010.519387)

72 Pi-Sunyer X, Astrup A, Fujioka K, Greenway F, Halpern A, Krempf M, Lau DC, le Roux CW, Violante Ortiz R, Jensen CB et al. A randomized, controlled trial of $3.0 \mathrm{mg}$ of liraglutide in weight management. New England Journal of Medicine 2015373 11-22. (doi:10.1056/NEJMoa1411892)

73 Ebbeling CB, Pawlak DB \& Ludwig DS. Childhood obesity: publichealth crisis, common sense cure. Lancet 2002360 473-482. (doi:10.1016/S0140-6736(02)09678-2)

74 Field AE, Austin S, Taylor C, Malspeis S, Rosner B, Rockett HR, Gillman MW \& Colditz GA. Relation between dieting and weight change among preadolescents and adolescents. Pediatrics 2003 112 900-906. (doi:10.1542/peds.112.4.900)

75 Norris SL, Zhang X, Avenell A, Gregg E, Schmid CH \& Lau J. Long-term non-pharmacological weight loss interventions for adults with prediabetes. Cochrane Library 200518 CD005270.
76 Mann T, Tomiyama AJ, Westling E, Lew A-M, Samuels B \& Chatman J. Medicare's search for effective obesity treatments: diets are not the answer. American Psychologist 200762220. (doi:10.1037/0003-066X.62.3.220)

77 Stice E, Cameron RP, Killen JD, Hayward C \& Taylor CB. Naturalistic weight-reduction efforts prospectively predict growth in relative weight and onset of obesity among female adolescents. Journal of Consulting and Clinical Psychology 199967 967-974. (doi:10.1037/0022-006X.67.6.967)

78 Dietz WH \& Robinson TN. Clinical practice. Overweight children and adolescents. New England Journal of Medicine 2005352 2100-2109. (doi:10.1056/NEJMcp043052)

79 August GP, Caprio S, Fennoy I, Freemark M, Kaufman FR, Lustig RH, Silverstein JH, Speiser PW, Styne DM, Montori VM et al. Prevention and treatment of pediatric obesity: an endocrine society clinical practice guideline based on expert opinion. Journal of Clinical Endocrinology and Metabolism 200893 4576-4599. (doi:10.1210/jc.2007-2458)

80 Paulus GF, de Vaan LE, Verdam FJ, Bouvy ND, Ambergen TA \& van Heurn LW. Bariatric surgery in morbidly obese adolescents: a systematic review and meta-analysis. Obesity Surgery 201525 860-878. (doi:10.1007/s11695-015-1581-2)

81 Kamath CC, Vickers KS, Ehrlich A, McGovern L, Johnson J, Singhal V, Paulo R, Hettinger A, Erwin PJ \& Montori VM. Clinical review: behavioral interventions to prevent childhood obesity: a systematic review and metaanalyses of randomized trials. Journal of Clinical Endocrinology and Metabolism 200893 4606-4615. (doi:10.1210/jc.2006-2411)

82 Whitlock EP, O'Connor EA, Williams SB, Beil TL \& Lutz KW. Effectiveness of weight management interventions in children: a targeted systematic review for the USPSTF. Pediatrics 2010125 e396-e418. (doi:10.1542/peds.2009-1955)

83 Kelly AS, Barlow SE, Rao G, Inge TH, Hayman LL, Steinberger J, Urbina EM, Ewing LJ, Daniels SR, American Heart Association Atherosclerosis, Hypertension, and Obesity in the Young Committee of the Council on Cardiovascular Disease in the Young, Council on Nutrition, Physical Activity and Metabolism, and Council on Clinical Cardiology. Severe obesity in children and adolescents: identification, associated health risks, and treatment approaches: a scientific statement from the American Heart Association. Circulation 2013128 1689-1712. (doi:10.1161/ CIR.0b013e3182a5cfb3)

84 Beamish AJ, Olbers T, Kelly AS \& Inge TH. Cardiovascular effects of bariatric surgery. Nature Reviews Cardiology 201613 730-743. (doi:10.1038/nrcardio.2016.162)

85 Beamish AJ, D'Alessio DA \& Inge TH. Controversial issues: when the drugs don't work, can surgery provide a different outcome for diabetic adolescents? Surgery for Obesity and Related Diseases 2015 11 946-948. (doi:10.1016/j.soard.2015.03.006)

86 Pinhas-Hamiel O \& Zeitler P. The global spread of type 2 diabetes mellitus in children and adolescents. Journal of Pediatrics 2005 146 693-700. (doi:10.1016/j.jpeds.2004.12.042)

87 Bloomgarden ZT. Type 2 diabetes in the young: the evolving epidemic. Diabetes Care 200427 998-1010. (doi:10.2337/ diacare.27.4.998)

88 Reinehr T, Kiess W, Kapellen T, Wiegand S, Holl RW, APV and DPV Wiss Study Group \& German Competence Net Obesity. Children with diabetes mellitus type 2 in Europe: an underserved population. Archives of Disease in Childhood 201095954. (doi:10.1136/adc.2010.187898)

89 Shah AS, D'Alessio D, Ford-Adams ME, Desai AP \& Inge TH. Bariatric surgery: a potential treatment for type 2 diabetes in youth. Diabetes Care 201639 934-940. (doi:10.2337/dc16-0067)

90 Schauer PR, Mingrone G, Ikramuddin S \& Wolfe B. Clinical outcomes of metabolic surgery: efficacy of glycemic control, weight loss, and remission of diabetes. Diabetes Care 201639 902-911. (doi:10.2337/dc16-0382) 
91 American Diabetes Association. 6. Obesity management for the treatment of type 2 diabetes. Diabetes Care 201639 (Supplement 1) S47-S51. (doi:10.2337/dc16-S009)

92 Beamish AJ. Bariatric surgery for obese adolescents to prevent type 2 diabetes. BMJ 2016353 i2977. (doi:10.1136/bmj.i2977)

93 RCSEng/DoH The Royal College of Surgeons of England and the Department of Health. The Higher Risk General Surgical Patient: towards improved care for a forgotten group, 2011.

94 Sjostrom L, Peltonen M, Jacobson P, Ahlin S, AnderssonAssarsson J, Anveden A, Bouchard C, Carlsson B, Karason K, Lonroth $\mathrm{H}$ et al. Association of bariatric surgery with longterm remission of type 2 diabetes and with microvascular and macrovascular complications. JAMA $20143112297-2304$. (doi:10.1001/jama.2014.5988)

95 Inge TH, Jenkins TM, Zeller M, Dolan L, Daniels SR, Garcia VF, Brandt ML, Bean J, Gamm K \& Xanthakos SA. Baseline BMI is a strong predictor of nadir BMI after adolescent gastric bypass. Journal of Pediatrics 2010156 103-108.e101. (doi:10.1016/j. jpeds.2009.07.028)

96 Brei MN \& Mudd S. Current guidelines for weight loss surgery in adolescents: a review of the literature. Journal of Pediatrics Health Care 201428 288-294. (doi:10.1016/j.pedhc.2013.04.005)

97 Michalsky M, Reichard K, Inge T, Pratt J, Lenders C, American Society for M \& Bariatric S. ASMBS pediatric committee best practice guidelines. Surgery for Obesity and Related Diseases $2012 \mathbf{8}$ 1-7. (doi:10.1016/j.soard.2011.09.009)

98 Must A \& Strauss RS. Risks and consequences of childhood and adolescent obesity. International Journal of Obesity and Related Metabolic Disorders 199923 S2-S11. (doi:10.1038/ sj.ijo.0800852)

99 Twig G, Yaniv G, Levine H, Leiba A, Goldberger N, Derazne E, Ben-Ami Shor D, Tzur D, Afek A, Shamiss A et al. Body-mass index in 2.3 million adolescents and cardiovascular death in adulthood. New England Journal of Medicine $20163742430-2440$. (doi:10.1056/NEJMoa1503840)

100 Mason EE \& Ito C. Gastric bypass. Annals of Surgery 1969170 329-339. (doi:10.1097/00000658-196909010-00003)

101 Chang SH, Stoll CR, Song J, Varela JE, Eagon CJ \& Colditz GA. The effectiveness and risks of bariatric surgery: an updated systematic review and meta-analysis, 2003-2012. JAMA Surgery 2014149 275-287. (doi:10.1001/jamasurg.2013.3654)

102 Sandblom G, Videhult P, Crona Guterstam Y, Svenner A \& SadrAzodi O. Mortality after a cholecystectomy: a population-based study. HPB 201517 239-243. (doi:10.1111/hpb.12356)

103 Sinha S, Hofman D, Stoker DL, Friend PJ, Poloniecki JD, Thompson MM \& Holt PJ. Epidemiological study of provision of cholecystectomy in England from 2000 to 2009: retrospective analysis of Hospital Episode Statistics. Surgical Endoscopy 201327 162-175. (doi:10.1007/s00464-012-2415-0)

104 Staalesen T, Olbers T, Dahlgren J, Fagevik Olsen M, Flodmark CE, Marcus C \& Elander A. Development of excess skin and request for body-contouring surgery in postbariatric adolescents. Plastic and Reconstructive Surgery 2014134 627-636. (doi:10.1097/ PRS.0000000000000515)

105 Mallory GN, Macgregor AM \& Rand CS. The influence of dumping on weight loss after gastric restrictive surgery for morbid obesity. Obesity Surgery 19966 474-478. (doi:10.1381/09 6089296765556368)

106 Laurenius A \& Engstrom M. Early dumping syndrome is not a complication but a desirable feature of Roux-en-Y gastric bypass surgery. Clinical Obesity 20166 332-340. (doi:10.1111/ cob.12158)

107 Alqahtani A, Elahmedi M \& Al Qahtani AR. Laparoscopic sleeve gastrectomy in children younger than 14 years: refuting the concerns. Annals of Surgery 2016263 312-319. (doi:10.1097/ SLA.0000000000001278)
108 Marshall WA \& Tanner JM. Variations in pattern of pubertal changes in girls. Archives of Disease in Childhood 196944 291-303. (doi:10.1136/adc.44.235.291)

109 Marshall WA \& Tanner JM. Variations in the pattern of pubertal changes in boys. Archives of Disease in Childhood 197045 13-23. (doi:10.1136/adc.45.239.13)

110 Beamish AJ, Gronowitz E, Olbers T, Flodmark CE, Marcus C \& Dahlgren J. Body composition and bone health in adolescents after Roux-en-Y gastric bypass for severe obesity. Pediatric Obesity 2016 Epub ahead of print. (doi: 10.1111/ijpo.12134)

111 Kaulfers AM, Bean JA, Inge TH, Dolan LM \& Kalkwarf HJ. Bone loss in adolescents after bariatric surgery. Pediatrics $2011 \mathbf{1 2 7}$ e956-e961. (doi:10.1542/peds.2010-0785)

112 Holick MF. Vitamin D deficiency. New England Journal of Medicine 2007357 266-281. (doi:10.1056/NEJMra070553)

113 Gordon CM, DePeter KC, Feldman HA, Grace E \& Emans SJ. Prevalence of vitamin D deficiency among healthy adolescents. Archives of Pediatrics and Adolescent Medicine 2004158 531-537. (doi:10.1001/archpedi.158.6.531)

114 Bal BS, Finelli FC, Shope TR \& Koch TR. Nutritional deficiencies after bariatric surgery. Nature Reviews Endocrinology 20128 544-556. (doi:10.1038/nrendo.2012.48)

115 von Drygalski A \& Andris DA. Anemia after bariatric surgery: more than just iron deficiency. Nutrition in Clinical Practice 200924 217-226. (doi:10.1177/0884533609332174)

116 Towbin A, Inge TH, Garcia VF, Roehrig HR, Clements RH, Harmon CM \& Daniels SR. Beriberi after gastric bypass surgery in adolescence. Journal of Pediatrics 2004145 263-267. (doi:10.1016/j.jpeds.2004.04.051)

117 Miras AD \& le Roux CW. Mechanisms underlying weight loss after bariatric surgery. Nature Reviews Gastroenterology and Hepatology 201310 575-584. (doi:10.1038/nrgastro.2013.119)

118 Chang P \& Friedenberg F. Obesity and GERD. Gastroenterology Clinics of North America 201443 161-173. (doi:10.1016/j. gtc.2013.11.009)

119 Chiu S, Birch DW, Shi X, Sharma AM \& Karmali S. Effect of sleeve gastrectomy on gastroesophageal reflux disease: a systematic review. Surgery for Obesity and Related Diseases 20117 510-515. (doi:10.1016/j.soard.2010.09.011)

120 De Groot NL, Burgerhart JS, Van De Meeberg PC, de Vries DR, Smout AJ \& Siersema PD. Systematic review: the effects of conservative and surgical treatment for obesity on gastrooesophageal reflux disease. Alimentary Pharmacology and Therapeutics 200930 1091-1102. (doi:10.1111/j.13652036.2009.04146.x)

121 Scozzari G, Trapani R, Toppino M \& Morino M. Esophagogastric cancer after bariatric surgery: systematic review of the literature. Surgery for Obesity and Related Diseases 20139 133-142. (doi:10.1016/j.soard.2012.10.002)

122 Bhaskaran K, Douglas I, Forbes H, dos-Santos-Silva I, Leon DA \& Smeeth L. Body-mass index and risk of 22 specific cancers: a population-based cohort study of 5.24 million UK adults. Lancet 2014384 755-765. (doi:10.1016/S0140-6736(14)60892-8)

123 Calle EE \& Kaaks R. Overweight, obesity and cancer: epidemiological evidence and proposed mechanisms. Nature Reviews Cancer 20044 579-591. (doi:10.1038/nrc1408)

124 Sjöström L, Gummesson A, Sjöström CD, Narbro K, Peltonen M, Wedel H, Bengtsson C, Bouchard C, Carlsson B \& Dahlgren S. Effects of bariatric surgery on cancer incidence in obese patients in Sweden (Swedish Obese Subjects Study): a prospective, controlled intervention trial. Lancet Oncology 200910 653-662. (doi:10.1016/S1470-2045(09)70159-7)

125 Christou NV, Lieberman M, Sampalis F \& Sampalis JS. Bariatric surgery reduces cancer risk in morbidly obese patients. Surgery for Obesity and Related Diseases 20084 691-695. (doi:10.1016/j. soard.2008.08.025) 
126 Adams TD, Gress RE, Smith SC, Halverson RC, Simper SC, Rosamond WD, LaMonte MJ, Stroup AM \& Hunt SC. Long-term mortality after gastric bypass surgery. New England Journal of Medicine 2007357 753-761. (doi:10.1056/NEJMoa066603)

127 Censani M, Conroy R, Deng L, Oberfield SE, McMahon DJ, Zitsman JL, Leibel RL, Chung WK \& Fennoy I. Weight loss after bariatric surgery in morbidly obese adolescents with MC4R mutations. Obesity 201422 225-231. (doi:10.1002/ oby.20511)

128 Aslan IR, Ranadive SA, Ersoy BA, Rogers SJ, Lustig RH \& Vaisse C. Bariatric surgery in a patient with complete MC4R deficiency. International Journal of Obesity 201135 457-461. (doi:10.1038/ ijo.2010.168)

129 Scheimann AO, Butler MG, Gourash L, Cuffari C \& Klish W. Critical analysis of bariatric procedures in Prader-Willi syndrome. Journal of Pediatric Gastroenterology and Nutrition 200846 80-83. (doi:10.1097/01.mpg.0000304458.30294.31)

130 Warschburger P. The unhappy obese child. International Journal of Obesity 200529 S127-S129. (doi:10.1038/sj.ijo.0803097)

131 Alqahtani AR, Antonisamy B, Alamri H, Elahmedi M \& Zimmerman VA. Laparoscopic sleeve gastrectomy in 108 obese children and adolescents aged 5 to 21 years. Annals of Surgery 2012 256 266-273. (doi:10.1097/SLA.0b013e318251e92b)

132 Angrisani L, Santonicola A, Iovino P, Formisano G, Buchwald H \& Scopinaro N. Bariatric Surgery Worldwide 2013. Obesity Surgery 201525 1822-1832. (doi:10.1007/s11695-015-1657-z)

133 Janicke DM, Steele RG, Gayes LA, Lim CS, Clifford LM, Schneider EM, Carmody JK \& Westen S. Systematic review and meta-analysis of comprehensive behavioral family lifestyle interventions addressing pediatric obesity. Journal of Pediatric Psychology 201439 809-825. (doi:10.1093/jpepsy/jsu023)

134 Summerbell CD, Ashton V, Campbell KJ, Edmunds L, Kelly $\mathrm{S} \&$ Waters E. Interventions for treating obesity in children. Cochrane Database of Systematic Reviews 2003 CD001872. (doi:10.1002/14651858.CD001872)

135 Seo DC \& Sa J. A meta-analysis of obesity interventions among U.S. minority children. Journal of Adolescent Health 201046 309-323. (doi:10.1016/j.jadohealth.2009.11.202)

136 Kitzmann KM, Dalton WT, 3rd, Stanley CM, Beech BM, Reeves TP, Buscemi J, Egli CJ, Gamble HL \& Midgett EL. Lifestyle interventions for youth who are overweight: a meta-analytic review. Health Psychology 201029 91-101. (doi:10.1037/ a0017437)

137 Wilfley DE, Tibbs TL, Van Buren D, Reach KP, Walker MS \& Epstein LH. Lifestyle interventions in the treatment of childhood overweight: a meta-analytic review of randomized controlled trials. Health Psychology 200726 521. (doi:10.1037/02786133.26.5.521)

138 O'Kane M, Pinkney J, Aasheim E, Barth J, Batterham R $\&$ Welbourn R. BOMSS guidelines on perioperative and postoperative biochemical monitoring and micronutrient replacement for patients undergoing bariatric surgery. Adopted by BOMSS Council September 2014, 2015.

139 Olbers T, Beamish AJ, Gronowitz E, Flodmark CE, Dahlgren J, Bruze G, Ekbom K, Friberg P, Göthberg G, Järvholm K et al. Laparoscopic Roux-en-Y gastric bypass in adolescents with severe obesity (AMOS): a prospective five-year Swedish nationwide study (AMOS). The Lancet: Diabetes \& Endocrinology 2017 In Press. (doi:10.1016/S2213-8587(16)30424-7)

140 Inge TH, Jenkins TM, Xanthakos SA, Dixon JB, Daniels SR, Zeller MH \& Helmrath MA. Long-term outcomes of bariatric surgery in adolescents with severe obesity (FABS-5+): a prospective follow-up analysis. The Lancet: Diabetes \& Endocrinology 2017 In Press. (doi:10.1016/S2213-8587(16)30315-1)

141 Blume CA, Boni CC, Casagrande DS, Rizzolli J, Padoin AV \& Mottin CC. Nutritional profile of patients before and after Rouxen-Y gastric bypass: 3-year follow-up. Obesity Surgery 201222 1676-1685. (doi:10.1007/s11695-012-0696-y)

142 Gehrer S, Kern B, Peters T, Christoffel-Courtin C \& Peterli R. Fewer nutrient deficiencies after laparoscopic sleeve gastrectomy (LSG) than after laparoscopic Roux-Y-gastric bypass (LRYGB) - a prospective study. Obesity Surgery 201020 447-453. (doi:10.1007/ s11695-009-0068-4)

143 Brolin RE, Gorman JH, Gorman RC, Petschenik AJ, Bradley LJ, Kenler HA \& Cody RP. Are vitamin B12 and folate deficiency clinically important after roux-en-Y gastric bypass? Journal of Gastrointestinal Surgery 19982 436-442. (doi:10.1016/S1091255X(98)80034-6)

144 Madan AK, Orth WS, Tichansky DS \& Ternovits CA. Vitamin and trace mineral levels after laparoscopic gastric bypass. Obesity Surgery 200616 603-606. (doi:10.1381/096089206776945057)

145 Hollowell JG, Van Assendelft OW, Gunter EW, Lewis BG, Najjar M \& Pfeiffer C. Hematological and Iron-Related Analytes-Reference Data for Persons Aged 1 Year and Over: United States, 1988-1994. Vital and health statistics. Series 11, Data from the national health survey. 1998 Dec(243): 1-78. Available at: http://europepmc.org/ abstract/med/10222835.

146 Wright JD, Bialostosky K, Gunter EW, Carroll MD, Najjar MF, Bowman BA \& Johnson CL. Blood Folate and Vitamin B12: United States, 1988-1994. Vital and health statistics. Series 11, Data from the national health survey. $1998 \operatorname{Dec}(\mathbf{2 4 3})$ : 1-78. Available at: http://europepmc.org/abstract/med/10222835

Received 2 November 2016

Revised version received 8 December 2016

Accepted 10 January 2017 